\title{
Spontaneous orientation polarization in organic light-emitting diodes
}

\author{
Yutaka Noguchi ${ }^{1 *}$, Wolfgang Brütting ${ }^{2}$, and Hisao Ishii ${ }^{3}$ \\ ${ }^{1}$ School of Science and Technology, Meiji University, Kanagawa 214-8571, Japan \\ ${ }^{2}$ Institute of Physics, University of Augsburg, 86135 Augsburg, Germany \\ ${ }^{3}$ Center for Frontier Science, Chiba University, Chiba 263-8522, Japan
}

\begin{abstract}
Spontaneous orientation polarization (SOP) is inherent in evaporated films of many organic semiconducting molecules with a permanent dipole moment. A significant electric field is formed in the film due to SOP. Consequently, the properties of organic light-emitting diodes (OLEDs) incorporating such films are influenced. The polarization charge appearing at heterointerfaces dominates the charge injection and accumulation properties. Moreover, SOP correlates to device degradation. In this article, we review SOP of organic semiconductor films and its influences on the device properties of OLEDs.
\end{abstract}

\section{Introduction}

Because of their anisotropic molecular shape, the majority of organic semiconductors exhibit orientational degrees of freedom. The microscopic orientation of molecules in thin films has strong impact on macroscopic properties such as charge carrier transport and optical properties as well as on the efficiency of organic light-emitting diodes (OLEDs). Initially, organic semiconductor films used in OLEDs had been typically considered as amorphous, where the molecules are "randomly oriented" and thus the macroscopic properties are isotropic. However, the amorphous state may have short-range order, even though it has no long-range order. Many spectroscopic studies have actually evaluated molecular orientation in noncrystalline organic semiconductor films since 1980s [1]. In 2009, Yokoyama et al. revisited the molecular orientation in the amorphous organic semiconductor films, and clearly demonstrated their impact on the device performances of OLEDs [2, 3]. Today, molecular orientation has been recognized as key parameter in modern OLEDs, e.g., the in-plane orientation of the emitter's transition dipole moment (TDM) enhances the light outcoupling efficiency, and $\pi$-stacking along the out-of-plane direction improves the electrical conductivity [2-9]. Furthermore, the asymmetric structure of the molecule induces a permanent dipole moment (PDM), and the average orientation of PDMs to a certain direction leads to macroscopic 
orientation polarization in the film [10]. Since orientation polarization induces polarization charges at heterointerfaces accompanied by an electric field in the film, one has to consider the device properties taking into account these factors besides molecular orientation itself [11-20].

In 1972, Kutzner reported spontaneous build-up of a surface potential up to $100 \mathrm{~V}$ at 100 $\mu \mathrm{m}$ for a multilayer of eight gases $\left({ }^{12} \mathrm{CO},{ }^{13} \mathrm{CO}, \mathrm{NO}, \mathrm{N}_{2} \mathrm{O}, \mathrm{SO}_{2}, \mathrm{NH}_{3}, \mathrm{H}_{2} \mathrm{O}\right.$, and acetone) physisorbed on a cold surface below $100 \mathrm{~K}$ [21]. The surface potential originates from spontaneous ordering of PDMs, i.e., spontaneous orientation polarization (SOP). Since then, the SOP of condensates of water ice, alcohols, ketones, ethers, and other materials have been widely investigated [22-30]. The PDM of these molecules are typically less than $0.5 \mathrm{D}$, and the electric field formed due to SOP is in the range of $1-120 \mathrm{mV} / \mathrm{nm}$ at around $40 \mathrm{~K}$. The negative electric field, corresponding to the negative end of PDM toward the vacuum side, has been observed as well as the positive electric field, e.g., $\mathrm{H}_{2} \mathrm{O}(1.85 \mathrm{D})$ : $-36 \mathrm{mV} / \mathrm{nm}$ at $30 \mathrm{~K}$ [29], $\mathrm{CF}_{3} \mathrm{Cl}$ (0.5 D): $-42.5 \mathrm{mV} / \mathrm{nm}$ at $40 \mathrm{~K}$ [27], and $\mathrm{N}_{2} \mathrm{O}$ (0.167 D): $97 \mathrm{mV} / \mathrm{nm}$ at 40 $\mathrm{K}$ [26]. The SOP decays for the films deposited at higher temperatures and typically disappears around $80 \mathrm{~K}$.

Surprisingly, in the case of organic semiconductors, SOP occurs at room temperature. The first direct observation of SOP in organic semiconductors was reported by Ito et al. in 2002 [10]. They observed the surface potential of a $\mathrm{Alq}_{3}$ film, which linearly grows with increasing film thickness. The surface potential reaches $28 \mathrm{~V}$ at $560 \mathrm{~nm}$, thus a so-called giant surface potential (GSP) is formed; however, GSP diminishes by light absorption of the $\mathrm{Alq}_{3}$ film. Complementary studies using optical second harmonic generation revealed that GSP originates from SOP, i.e., the spontaneous order of the PDMs of $\mathrm{Alq}_{3}[10,31]$. At the initial stage, researchers have focused on the photoinduced decay mechanism of GSP mainly motivated by the interests of fundamental material science rather than device physics [10, 32$35]$.

GSP/SOP is not a unique property of $\mathrm{Alq}_{3}$. Noguchi et al. have revealed that GSP is quite common in the evaporated films of OLED materials, including thermally activated delayed fluorescence (TADF) emitters [36-38], and various kinds of emitters and electron transporters $[16,39]$. However, the mechanism of spontaneous formation of orientation polarization is still incompletely understood. Isoshima et al. proposed the "asymmetric dice model" in which the driving force of the molecular orientation is attributed to the biased distribution of the stable posture of molecules on the film surface due to the asymmetric molecular shape [40]. Their model qualitatively explained the GSP characteristics of $\mathrm{Alq}_{3}$ and its derivative $\left(\mathrm{Al}(7-\mathrm{prq})_{3}\right)$ films. Recently, Friederich et al. have succeeded to mimic GSP of several 
materials using atomistic simulations [41]. They pointed out that short-range van der Waals interactions between the molecule and the surface during deposition dominate the driving force of the anisotropic molecular orientation, while intermolecular dipole-dipole interactions suppress the orientation degree. The contribution of PDM interaction to the SOP formation is also supported by experimental results. Brütting et al. reported SOP in the guest-host systems consisting of polar and nonpolar molecules [42, 43]. The degree of PDM orientation is enhanced by diluting the polar molecules in a nonpolar host, which indicates that the PDM interaction acts as a negative factor to the SOP formation.

Because of the photoinduced decay nature [10, 31-33], GSP has initially not been considered as an important parameter in terms of device properties. People have believed that no influences remain in actual devices of OLEDs after vanishing GSP due to the absorption of the ambient light and emission from the device itself. However, interestingly, Berleb et al. reported the influence of SOP on the charge injection and accumulation characteristics of a $\mathrm{Alq}_{3}$-based OLED in 2000, that is two years earlier than the first GSP report. They concluded on the presence of "fixed negative interfacial charge" between $\mathrm{Alq}_{3}$ and $\alpha$-NPD layers by using impedance spectroscopy [11]. Eight years later, Noguchi et al. pointed out that the interface charge and GSP have a common origin, namely the polarization charge due to SOP in the evaporated film $[13,16]$. SOP is maintained in actual devices and thus induces fixed charges at the heterojunctions in the devices. Their results also suggest an alternative mechanism of the GSP decay which was under debate at that time [10, 32-35]; the molecular order does not vanish due to the light absorption, but GSP decays due to the photo-generated carriers in the film.

The negative polarization charge due to SOP at the $\alpha$-NPD/Alq 3 interface causes hole injection at voltages even lower than the built-in voltage of the device $[11,12]$. The injected holes are accumulated at the interface to compensate the negative interface charge during device operation. Importantly, the accumulated charge is the real charge though the interface charge is polarization charge, and the amount is comparable to the maximum amount of the accumulated charge in operating OLEDs [16,44-47]. The presence of the accumulated charge near the emission zone can enhance the recombination probability, but the charged species can also act as an exciton quencher [48-52]. Moreover, the concentration of emission zone leads a faster degradation [50,53]. On the other hand, the positive polarization charge at the $\mathrm{Alq}_{3} /$ cathode interface is suggested to assist the electron injection through a formation of the electric double layer or gap states at the interface $[18,54,55]$.

Polar films are included in common organic thin film devices, since PDM is inherent to 
many organic semiconductors. SOP has not been considered as a significant factor to the device performance, though it may be used unintentionally. In terms of device optimization, SOP should be taken into account as well as other common material properties, such as the energy levels and charge carrier mobility. In this review, we describe the current understanding of SOP and its influences on the device properties.

\section{Spontaneous orientation polarization in organic films}

\subsection{Basics of SOP and GSP}

We consider a thin film composed of polar molecules where the film has a spontaneous polarization $\mathbf{P}_{0}$ (Fig. 1). $\mathbf{P}_{0}$ is defined as the net PDM per unit volume, i.e., $\mathbf{P}_{0}=\sum_{i} \mathbf{p}_{i} / L$, where $\mathbf{p}_{i}$ is the PDM of $i$-th molecule and $L$ is the volume of the film. If the film consists of a single component, the contribution of each molecule along the surface normal (unit vector: $\hat{\mathbf{z}})$ is given by

$$
\mathbf{p}_{i} \cdot \hat{\mathbf{z}}=p \cos \theta_{i}
$$

thus,

$$
P_{0}=\mathbf{P}_{0} \cdot \hat{\mathbf{z}}=\frac{p \sum_{i} \cos \theta_{i}}{L}=p\langle\cos \theta\rangle n
$$

where $n$ is the density of the molecule, and $\langle\cos \theta\rangle$ is the average orientation degree of PDM with respect to the surface normal direction, namely,

$$
\langle\cos \theta\rangle=\frac{\sum_{i} \cos \theta_{i}}{n L} .
$$

Note that $\sigma=P_{0}$ corresponds to the polarization charge density induced on the film surface. If we assume a certain distribution function, the average orientation degree can also be described as [43]

$$
\langle\cos \theta\rangle=\frac{\sum_{k} \Phi\left(\theta_{k}\right) \cos \theta_{k}}{n L} .
$$

Here, $\Phi\left(\theta_{k}\right)$ indicates the number of molecule whose PDM is pointing to a particular orientation angle, $\theta_{k}$, in the volume. Because of the nonlinear (cosine) contribution of PDM orientation angle to SOP, the most preferential orientation angle of PDM, $\theta_{\mathrm{m}}$, does not generally correspond to the average orientation degree. Therefore, Eq. (4) is useful to investigate the relations between SOP and a molecular orientation [43].

The spontaneous polarization forms the electric field $\left(\mathbf{P}_{0} / \varepsilon\right)$ in the film, where $\varepsilon$ is the dielectric constant. If $\mathbf{P}_{0}$ is uniform throughout the film, the potential at the film surface with 


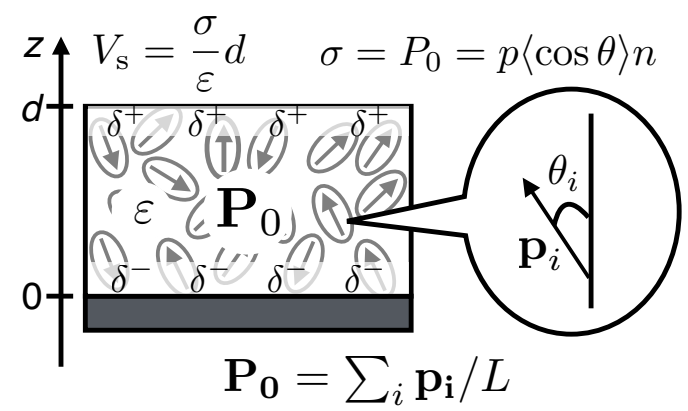

Fig. 1. Schematic illustration of the organic thin film with spontaneous orientation polarization. $L$ is the volume of the film.

reference to the substrate, $V_{\mathrm{s}}$, is given by

$$
V_{\mathrm{s}}=\int_{0}^{d} \mathbf{P}_{0} / \varepsilon \cdot \mathrm{d} \mathbf{z}=\frac{p\langle\cos \theta\rangle n}{\varepsilon} d=\frac{\sigma}{\varepsilon} d .
$$

where $d$ is the film thickness. The surface potential is proportional to the film thickness if $P_{0}$ is constant. This property appears in GSP, and thus the Kelvin probe method is often used to examine the SOP characteristics.

\subsection{Materials exhibiting SOP and their characteristics}

In Fig. 2, we summarize the molecules that exhibit SOP in the evaporated film $[10,18,39$, 40, 56, 57]. Calculated PDM intensities and GSP slopes reported in the previous studies are also shown. The molecules are mostly electron transport or emitting materials, including TADF [36-38] and Ir-based phosphorescent emitters, that are commonly used in OLEDs. In the research field of OLEDs, the molecular orientation is often evaluated in terms of TDM orientation $[3,9]$, therefore the materials are divided into three groups with different qualitative TDM orientations, namely, random, unknown, and horizontal.

Figure 3 shows the surface potential of the evaporated films of several materials. A GSP behavior, i.e., linear growth of the surface potential as a function of the film thickness, is observed indicating that SOP is inherent in these films. Some of them exhibit the surface potential exceeding several volts at film thicknesses over $\sim 100 \mathrm{~nm}$. Such behavior corresponds to a typical GSP characteristic. On the other hand, $\operatorname{Ir}(\mathrm{ppy})_{3}, \mathrm{mCP}$, and B3PyMPM films exhibit only a weak surface potential. As evident in the results, the GSP/SOP is very common in films with randomly oriented TDMs as well as in films with the horizontally oriented TDMs.

SOP appears in the films regardless of the TDM orientation type. The TDM orientation is typically evaluated by the optical measurements, where the head and tail of the molecule are indistinguishable because these methods evaluate the orientation of TDM intensity $\left(\propto\left\langle\cos ^{2} \theta_{t}\right\rangle\right.$, 

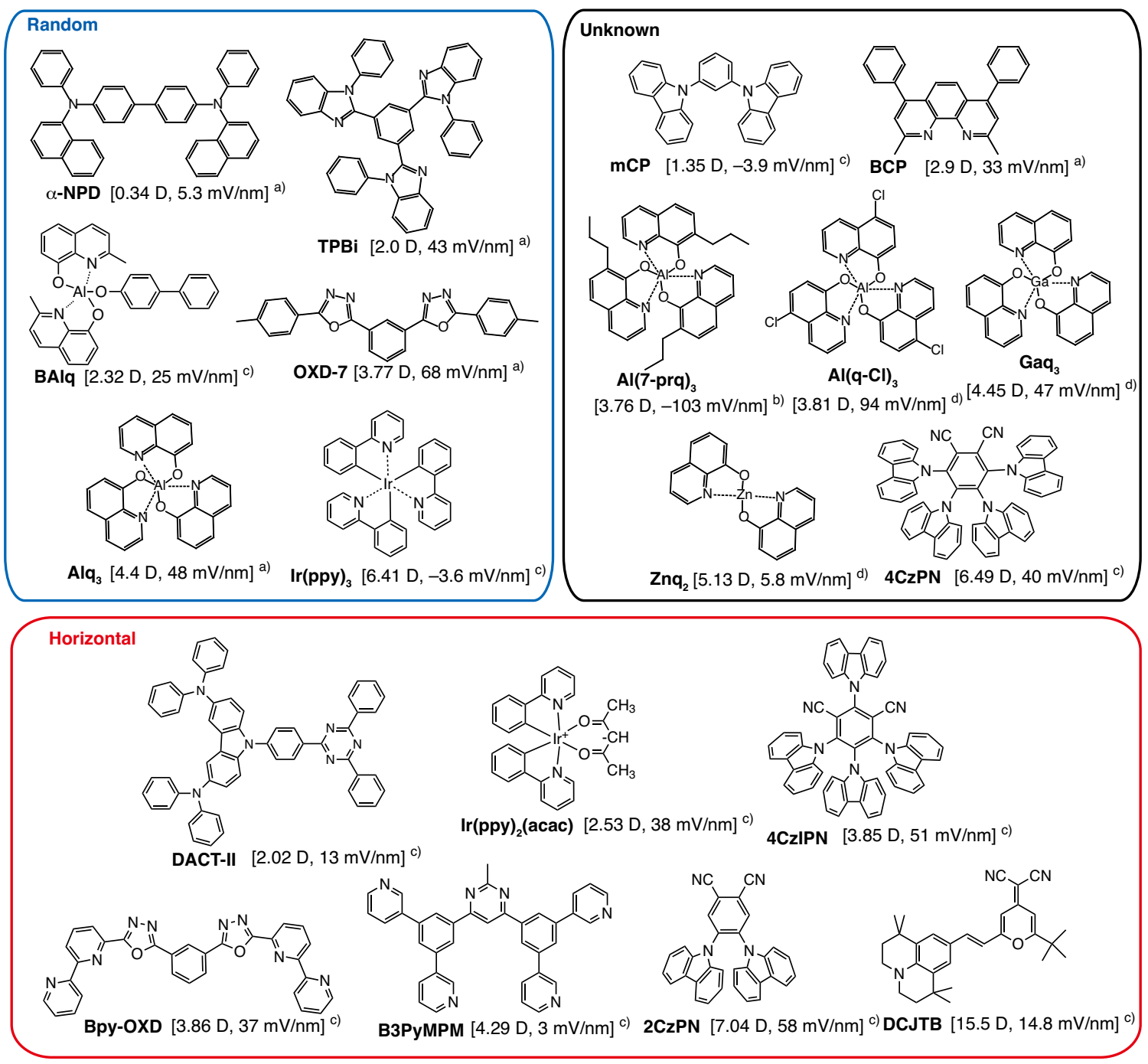

Fig. 2. Molecular structures of the organic materials exhibiting SOP in the evaporated film. The PDM of each molecule was calculated using Gaussian16 (DFT/B3LYP with a LANL2DZ basis set for Ir(ppy) ${ }_{3}$ and $\operatorname{Ir}(\mathrm{ppy})_{2}$ (acac), and a 6-31G* basis set for all other molecules). The reported GSP slope is indicated in the bracket, where the data indicated by a), b) ,c), and d) are taken from [16], [18], [39], and [56], respectively (see also Fig.5). The molecules were divided into three classes (random, unknown, and horizontal) based on their reported TDM orientations [2, 38, 58-62]. Note that $\alpha$-NPD, $\operatorname{Ir}(\mathrm{ppy})_{3}, \mathrm{mCP}$, and B3PyMPM show only a weak surface potential. The correct terminology of the molecule " $\alpha$-NPD" presented in this figure is "NPB", though both terms have been commonly used for this molecule. Adapted from ref. [39].

where $\theta_{\mathrm{t}}$ indicates the orientation angle of TDM). Moreover, random TDM orientation does not necessarily indicate random orientation of the symmetry axis of the molecule. For example, Murawski et al. reported that the molecular orientation in the $\operatorname{Ir}(\mathrm{ppy})_{3}$ film, which has a random TDM orientation [63]. On the other hand, SOP originates from the PDM orientation including its head-to-tail-direction, as it is proportional to $\langle\cos \theta\rangle$. SOP is therefore inherent 
(a)

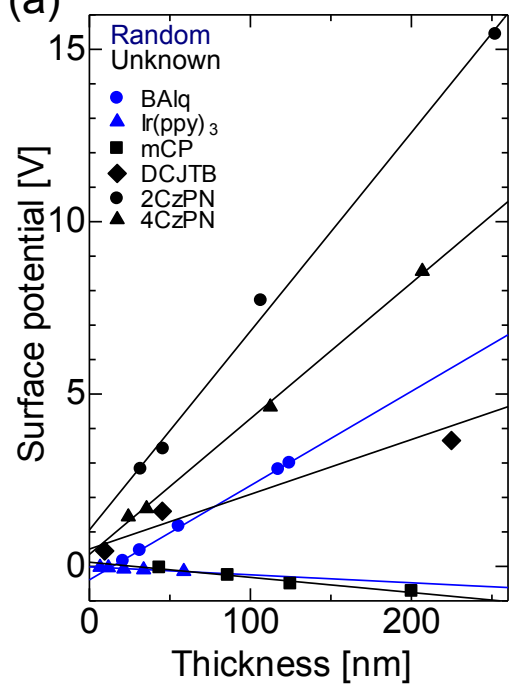

(b)

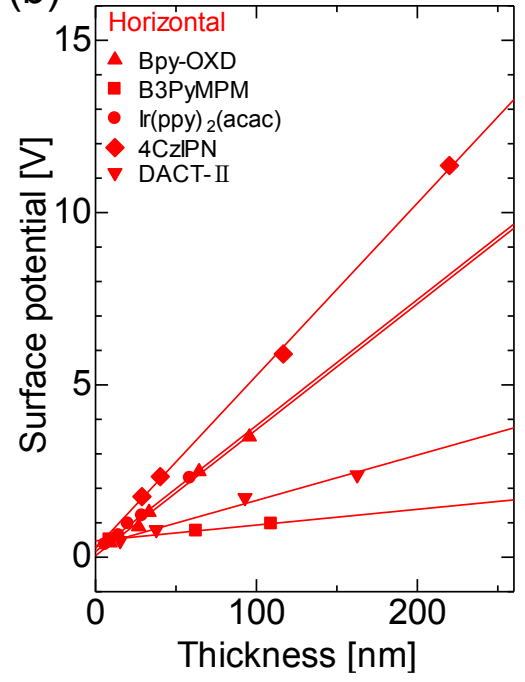

Fig. 3. Surface potentials of evaporated organic films as a function of film thickness. (a) "Random" and "Unknown” materials. (b) "Horizontal” materials. Reprinted with permission [39].

even in films with "randomly oriented" TDMs.

Of course, TDM and PDM orientations are not independent, as both of them relate to the orientation of the molecular frame. Therefore, the combined analysis of TDM and PDM orientations can be used for an accurate estimation of the molecular orientation. Morgenstern et al. proposed a method to determine the distribution range of the preferable molecular orientation angle based on the observation of TDM and PDM orientations (Fig. 4) [43]. They estimate the molecular orientation of typical phosphorescent emitters, $\operatorname{Ir}(\mathrm{ppy})_{3}$ and $\operatorname{Ir}(\mathrm{ppy})_{2}$ (acac), in a guest-host system, where the nonpolar molecule, CBP or UGH2, was used as a host. They found that the preferential alignment of $\operatorname{Ir}(\mathrm{ppy})_{2}(\mathrm{acac})$ has a narrow orientation distribution of the molecular $\mathrm{C}_{2}$ symmetry axis with its maximum close to the normal direction, whereas $\operatorname{Ir}(\mathrm{ppy})_{3}$ exhibits a random orientation of their $\mathrm{C}_{3}$ axis. Furthermore, they also estimate the degree of aggregation in $\operatorname{Ir}(\mathrm{ppy})_{2}$ (acac)-based guest-host systems, where the aggregates with an anti-parallel PDM alignment are formed above $10 \%$ dye content and they reduce SOP with keeping the TDM orientation unchanged.

Fig. 5 plots the absolute value of the GSP slope versus the dipole moment $p$ for films in previous studies $[10,18,39,40,56,57]$. The GSP slope is in the similar range of the electric field formed in the gases physisorbed on a cold surface (1-120 mV/nm at around $40 \mathrm{~K}$ ), though the PDM intensity of the organic semiconductors is typically greater than that of the gases [2629]. In addition, unlike the case of the physisorbed gases, most organic semiconductors exhibit positive GSP. The broken line in Fig. 5 indicates the average slope, excluding materials with 

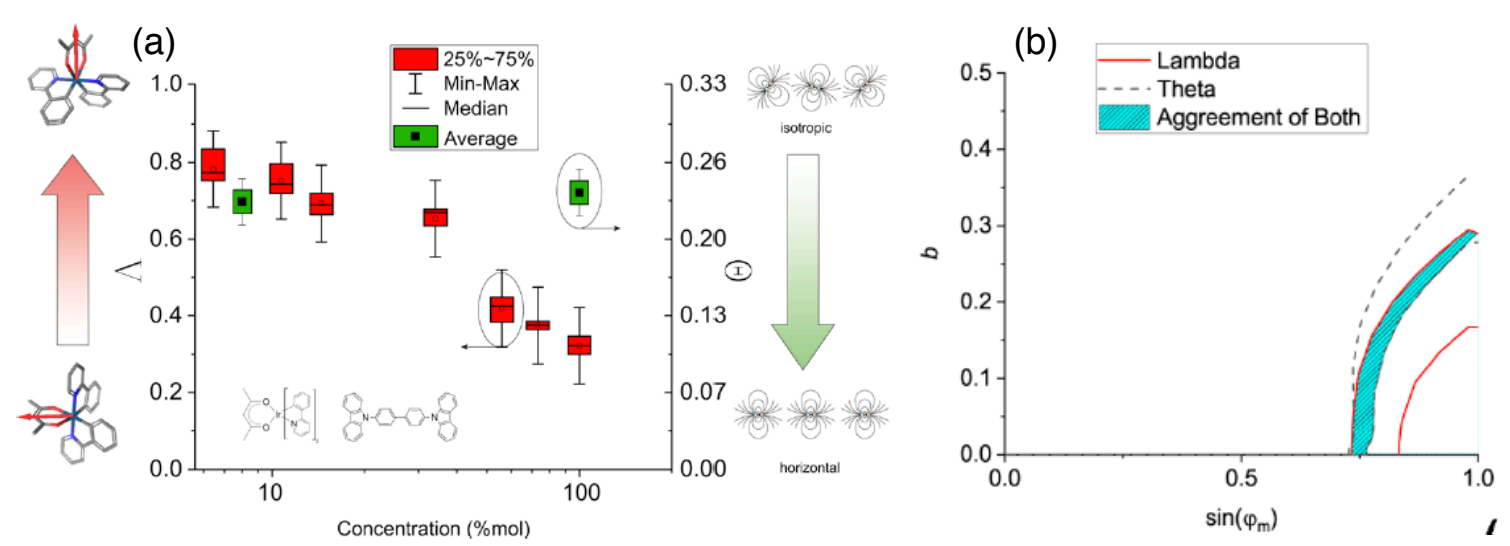

Fig. 4. (a) Experimentally determined orientation degrees of $\operatorname{PDM}(\Lambda)$ and $\operatorname{TDM}(\Theta)$ of the guest-host system, where $\operatorname{Ir}(\mathrm{ppy})_{2}$ (acac) and CBP is used as the guest and host, respectively. $\Lambda$ corresponds to $\langle\cos \theta\rangle$, while $\Theta$ corresponds to $\left\langle\cos ^{2} \theta_{\mathrm{t}}\right\rangle$ in the main text. (b) The possible orientations of molecular symmetry axes of $\operatorname{Ir}(\mathrm{ppy})_{2}$ (acac) estimated from the combined analysis of PDM and TDM orientations. The Gaussian distribution of the molecular orientation angle is assumed, where the peak angle is $\varphi_{\mathrm{m}}$ with a standard deviation of $b$. Note that the orientation angle is defined with reference to the in-plain axis. Reproduced with permission [43].

extremely high slope $\left(\mathrm{Al}(7 \mathrm{prq})_{3}, \mathrm{Al}(\mathrm{q}-\mathrm{Cl})_{3}\right)$ or low slope (DCJTB, $\operatorname{Ir}(\mathrm{ppy})_{3}, \mathrm{Znq}_{2}, \mathrm{~B} 3$ PyMPM, $\mathrm{mCP})$. The slope, which corresponds to $\eta=n\langle\cos \theta\rangle / \varepsilon$, is considered to measure the efficiency of SOP formation per PDM. Interestingly, several materials, such as $\mathrm{Alq}_{3}, \mathrm{BCP}, \mathrm{Bpy-OXD}$, and $\operatorname{Ir}(\text { ppy })_{2}$ (acac), plot close to the average slope, indicating that these materials form SOP with similar efficiencies. On the other hand, several materials, such as DCJTB, $\operatorname{Ir}(\mathrm{ppy})_{3}, \mathrm{Znq}_{2}$, B3PyMPM, and mCP, exhibit an extremely small $\eta$. Quantum chemical calculations revealed the electrostatic interaction energies (except dispersive forces) of a dimer of DCJTB, $\operatorname{Ir}(\text { ppy })_{3}$, $\mathrm{Znq}_{2}$, and B3PyMPM are particularly strong, suggesting that these molecules are likely to form aggregates with vanishing PDM alignment [39].

Although most materials show positive GSP (Fig. 5), negative GSP was also found in an evaporated film of an $\mathrm{Alq}_{3}$ derivative. This negative GSP in $\mathrm{Al}(7-\mathrm{Prq})_{3}$ film was discovered by Isoshima et al. [40]. Since not only the molecular structure but also PDM and molecular orbitals of $\mathrm{Al}(7-\mathrm{Prq})_{3}$ are similar to those of $\mathrm{Alq}_{3}$ [18], it is surprising that a small change in the ligand sphere of the molecule, i.e., attachment of propyl group, induces significant changes in GSP. This result suggests a possible mechanism for the formation of SOP. Isoshima et al. proposed an "asymmetric dice model", in which the statistics of stable positions of the molecule on the surface determine the molecular orientation [40].

The asymmetric dice model is consistent with the results recently reported by Friederich $e t$ al [41]. They demonstrated the atomistic simulations to mimic GSP of several materials, and 


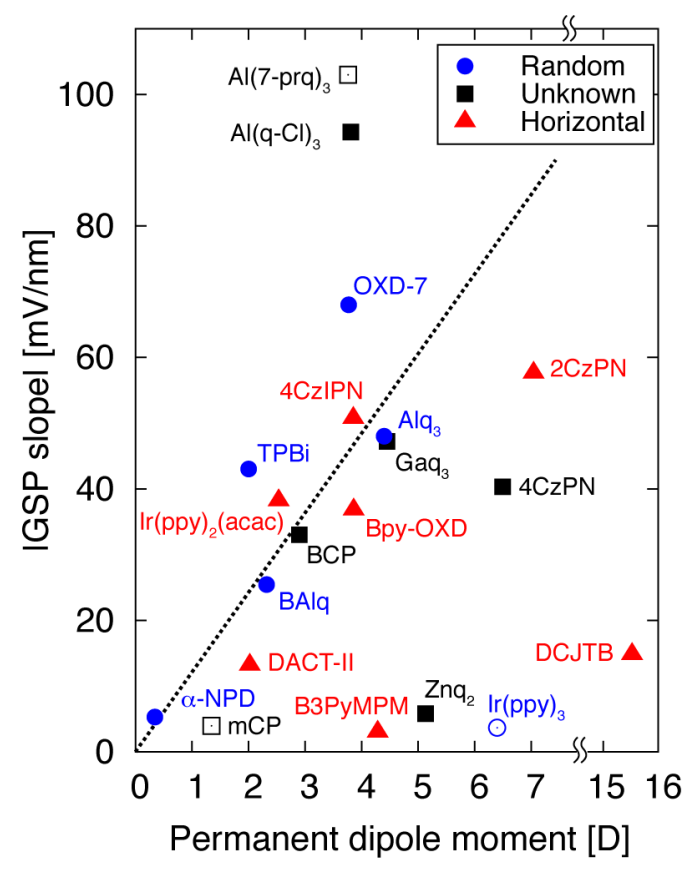

Fig. 5. Relationship between the absolute value of GSP slope and PDM intensity for various organic materials. Each symbol indicates the TDM orientation in evaporated films with random (blue circles), unknown (black squares), and horizontal (red triangle) molecular orientations. Open symbols indicate negative GSP. Note that the GSP slope for DCJTB was variable probably depending on the details of the film formation conditions. The GSP slope for DCJTB was observed from 7 to $25 \mathrm{mV} / \mathrm{nm}$, and the average was $14.8 \mathrm{mV} / \mathrm{nm}$. For TPBi, a larger GSP is also reported ( 70 mV/nm)[41]. Reprinted with permission [39].

pointed out van der Waals interactions between the molecule and the surface during deposition as the driving force of the anisotropic molecular orientation. Since the van der Waals force is valid within a short distance, the interactions are determined between the outermost parts of the molecule and those of adjacent molecules, where the shape of the molecule plays an important role $[64,65]$. They also reported that PDM interaction negatively contributes to the SOP formation, as suggested by the several experimental results [39, 42, 43].

\section{Influences of SOP on the device properties}

\subsection{Interface charge model}

The interface charge model describes how SOP affects the charge injection and accumulation behavior in the device $[11,12,16,20]$. We consider the charge injection voltage and charge accumulation characteristics of a bilayer device, where two organic layers with different polarization, $\mathbf{P}_{1}$ and $\mathbf{P}_{2}$, are sandwiched between bottom and top electrodes [Fig. 6(a)]. For simplicity, only hole injection and accumulation are assumed in the following case. 

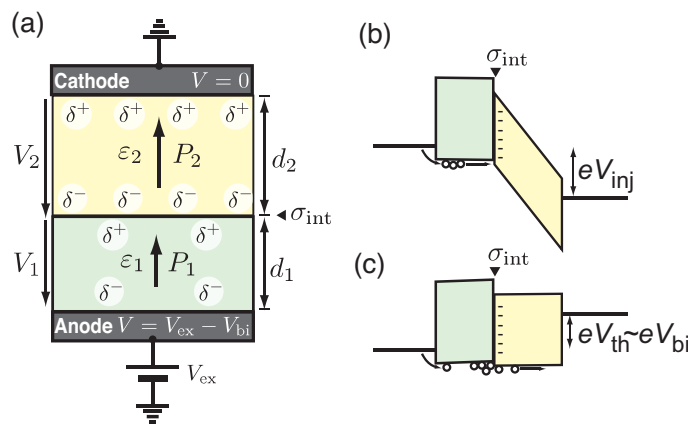

Fig. 6. (a) Schematic illustration of the orientation polarization in a bilayer device. The interface charge $\sigma_{\text {int }}$ is induced at the organic heterointerface due to the orientation polarization. (b), (c) Schematic illustrations of energy diagram at the hole injection voltage (b) and at the threshold voltage of the actual current (c). Adapted from Ref. [66].

The net polarization charge at the organic heterointerface is easily obtained as

$$
\sigma_{\text {int }}=\left(\mathbf{P}_{1}-\mathbf{P}_{2}\right) \cdot \hat{\mathbf{z}}=\varepsilon_{1} \frac{V_{\mathrm{s} 1}}{d_{1}}-\varepsilon_{2} \frac{V_{\mathrm{s} 2}}{d_{2}}
$$

where $V_{\mathrm{s} 1} / d_{1}$ and $V_{\mathrm{s} 2} / d_{2}$ correspond to the GSP slope of each film. Note that $\sigma_{\text {int }}$ is independent of the film thicknesses. When the external voltage $\left(V_{\mathrm{ex}}\right)$ is applied to the bottom electrode with reference to the top electrode, $V_{\mathrm{ex}}-V_{\mathrm{bi}}=V_{1}+V_{2}$ is valid, where $V_{1}$ and $V_{2}$ is the potential drop in the first and second layer, respectively, and $V_{\mathrm{bi}}$ is the built-in voltage. The built-in voltage originates from the work function difference between two electrodes and interface dipole at the contacts [67]. The electric field in the first layer should be positive when the hole injection from the bottom electrode occurs. This condition is independent from the energy barrier height at the electrode/organic film contact. The hole injection voltage $\left(V_{\text {inj }}\right)$ is thus given by $V_{\mathrm{ex}}$ when $V_{1} / d_{1}=0$ (Fig. 6(b)), namely,

$$
V_{\text {inj }}=V_{\text {bi }}+\left(\mathbf{P}_{1}-\mathbf{P}_{2}\right) \cdot \hat{\mathbf{z}} \frac{d_{2}}{\varepsilon_{2}}=V_{\text {bi }}+\frac{\sigma_{\text {int }}}{\varepsilon_{2}} d_{2},
$$

where the boundary condition at the organic heterointerface,

$$
\varepsilon_{1} \frac{V_{1}}{d_{1}}+\mathbf{P}_{1} \cdot \hat{\mathbf{z}}=\varepsilon_{2} \frac{V_{2}}{d_{2}}+\mathbf{P}_{2} \cdot \hat{\mathbf{z}}
$$

is used. Note that the hole injection voltage is proportional to the thickness of the second layer, if $\sigma_{\text {int }}$ is constant. This is the interface charge model proposed by Berleb et al. [11, 12]

The injected holes into the first layer are accumulated at the organic heterointerface, if the electric field in the second layer is negative. Note that this charge accumulation occurs regardless of the energy barrier height at the interface. When the conductance of the first layer is sufficiently high and the potential drop in the first layer is negligible small, the threshold voltage for hole injection into the second layer $\left(V_{\mathrm{th}}\right)$ equals to $V_{\mathrm{bi}}(\mathrm{Fig}$. 6(c)). The accumulated 


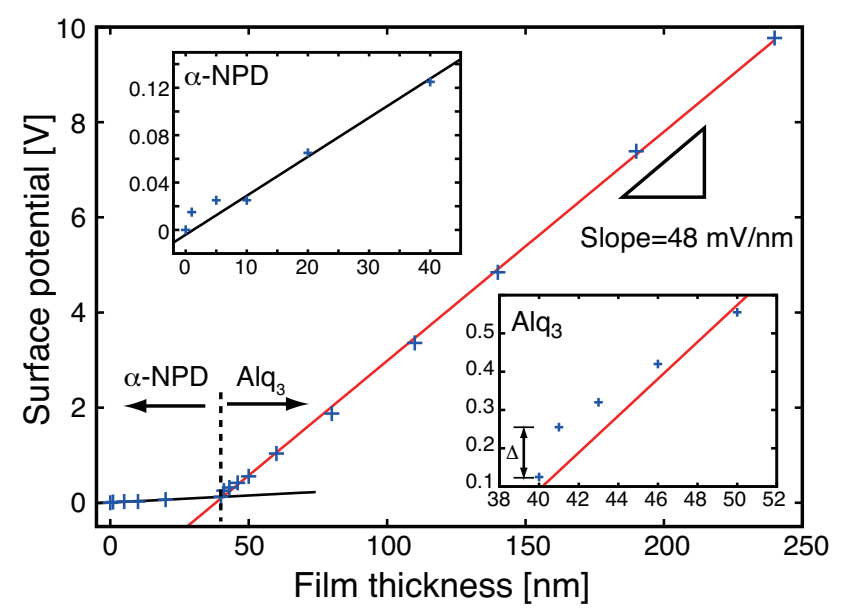

Fig. 7. The surface potential of the $\mathrm{Alq}_{3}$ and $\alpha$-NPD films as a function of film thickness. The $\mathrm{Alq}_{3}$ film was deposited on an $\alpha$-NPD film on an ITO substrate. The $\alpha$-NPD/Alq ${ }_{3}$ interface is located at a film thickness of 40 $\mathrm{nm}$. The surface potential of the $\mathrm{Alq}_{3}$ film grows linearly with a slope of $48 \mathrm{mV} / \mathrm{nm}$, although a nonlinear region appears within several nanometers from the interface (bottom inset). The potential jump at the $\mathrm{Alq}_{3} / \alpha$-NPD interface $(\Delta)$ suggests the presence of an interface dipole. The $\alpha$-NPD film also shows weak GSP behavior with a slope of ca. $5.3 \mathrm{mV} / \mathrm{nm}$ (top inset). Reprinted with permission [16].

charge density at the interface at $V_{\text {th }}$ is given by

$$
\sigma_{\mathrm{acc}}=\left(V_{\mathrm{th}}-V_{\mathrm{inj}}\right) \frac{\varepsilon_{2}}{d_{2}}=-\sigma_{\mathrm{int}}
$$

Therefore, the interface charge density can be estimated from capacitance-voltage $(C-V)$ measurement or displacement current measurement (DCM) of the bilayer device $[12,13]$. This simple model well explains the device characteristics below $V_{\text {th }}$ and the correlation between the interface charge density and the GSP slope [16].

\subsection{Charge accumulation in bilayer devices}

Figure 7 shows the surface potential characteristics of a bilayer structure of $\mathrm{Alq}_{3}$ on $\alpha$-NPD layer as a function of film thickness [16]. The surface potential is measured with reference to the ITO substrate. A clear GSP behavior is observed with a slope of $48 \mathrm{mV} / \mathrm{nm}$ in the $\mathrm{Alq}_{3}$ layer, and a weak GSP with a slope of $5.3 \mathrm{mV} / \mathrm{nm}$ in the $\alpha$-NPD layer. The net polarization charge induced at the interface is estimated to be $-1.2 \mathrm{mC} / \mathrm{m}^{2}$ from Eq.(6). Here, the relative dielectric constant of 3.2 and 3.3 is used for $\mathrm{Alq}_{3}$ and $\alpha$-NPD layer, respectively.

The estimated polarization charge density agrees well with the accumulation charge density at this interface. Figure 8 shows DCM curves of the $\alpha$-NPD/Alq ${ }_{3}$ bilayer device with various combinations of film thicknesses. DCM is a kind of $C-V$ measurement in which a triangular wave voltage is applied to the device and the current response including actual 

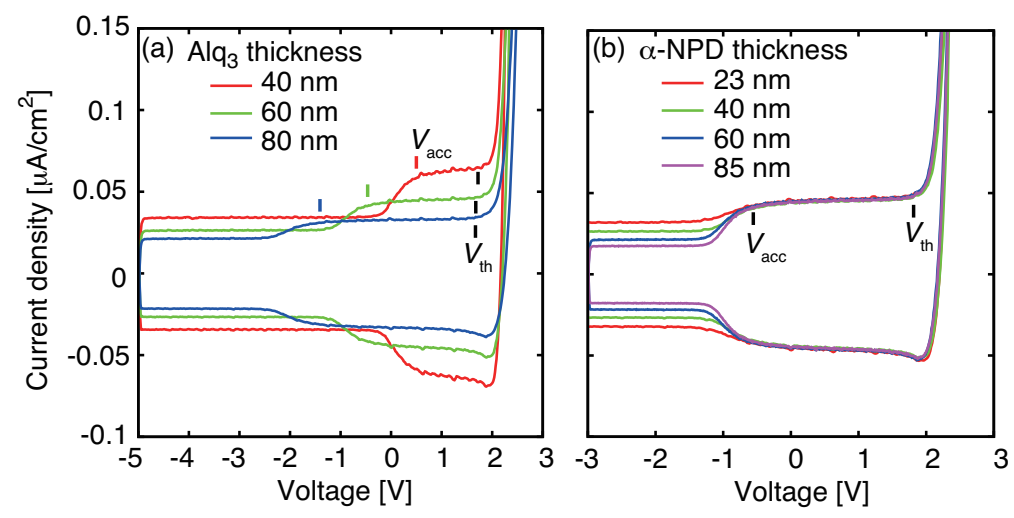

Fig. 8. (a), (b) DCM curves of the ITO/ $\alpha$-NPD/Alq $3 / \mathrm{Al}$ device for various film thicknesses. The $\alpha$-NPD and $\mathrm{Alq}_{3}$ film thicknesses are fixed at $40 \mathrm{~nm}$ (a) and $60 \mathrm{~nm}$ (b), respectively. The current density at the accumulation state depends only on the $\mathrm{Alq}_{3}$ film thickness, indicating that the injected charges are holes. The threshold voltage of the actual current $V_{\text {th }}$ is independent of the combinations of the film thickness, whereas $V_{\text {acc }}$ shifts to the negative side with increasing $\mathrm{Alq}_{3}$ film thickness. Thus, the polarity of interface charge is negative. Reprinted with permission [16]

and displacement current is measured [20, 68-70]. Since the displacement current is proportional to the apparent capacitance of the device, the charge injection and accumulation characteristics are examined. The accumulated charge density can be estimated by integrating the displacement current density from $V_{\text {acc }}$ to $V_{\text {th }}$, i.e., $1.1 \mathrm{mC} / \mathrm{m}^{2}$. This value is similar to the net polarization charge density $\left(-1.2 \mathrm{mC} / \mathrm{m}^{2}\right)$ at this interface and almost independent of the combination of the film thicknesses. Note that $V_{\text {acc }}$ is considered as the voltage at which the injected holes reach the interface, and from $V_{\text {inj }}$ to $V_{\text {acc }}$, the injected holes are accumulated in the bulk of the first layer, i.e., $\alpha$-NPD, rather than the interface $[17,20]$. Therefore Eq.(9) is modified to determine the $\sigma_{\text {acc }}$ from the DCM curves.

Similar results are obtained from the bilayer systems in which various polar molecules are used as the second layer. Figure 9 shows the relationship between the polarization charge density estimated from the GSP slope $\left(\sigma_{\text {int }}(\mathrm{GSP})\right)$ and the interface charge density estimated from the DCM curves $\left(\sigma_{\text {int }}(\mathrm{DCM})\right)$. The data points are located around the line with slope 1, indicating that the origin of the interface charge is the polarization charge due to SOP, and the polarization charge dominates the charge accumulation at the interface. Although the limited number of materials have been directly examined, at least if the device contains the materials shown in Fig. 2, the polarization charge would appear at the interface and modify the charge accumulation properties.

OLEDs work at applied biases higher than $V_{\mathrm{bi}}$. In this voltage region, the interface charge is compensated by the injected counter charge. Thus the electric field due to the interface charge 


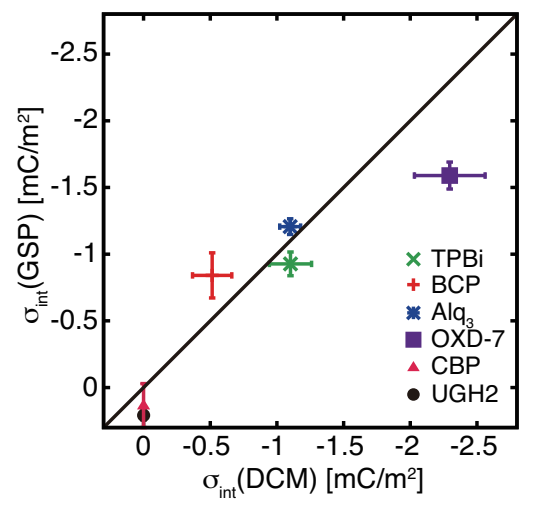

Fig. 9. Comparison between the interface charge density estimated from the GSP slope and DCM curves. The slope of the solid line is 1 . Reproduced with permission [16].

no longer affects device operation at least from the viewpoint of electrostatics. However, importantly, the interface charge is the polarization charge but the accumulated charge is the real charge. There are excess ionized molecules with the opposite polarity to the interface charge at the heterointerface. The ionized molecules near the emission zone can work as an exciton quencher and induce a molecular decomposition [48-52]. On the other hand, the accumulated charge defines the emission zone and enhances the charge carrier balance factor $[44,71]$. Since the interface charge density is comparable to the maximum amount of the accumulation charge density under device operation [44-47], this excess charge accumulation should be taken into account for detailed understandings of the device operation and degradation mechanisms.

\subsection{Charge injection at the metal/organic interface}

The interface charge dominates the charge injection voltage and minimum amount of accumulation charge density of a multilayer device under operation. Since the interface charge originates from SOP, there is the counter-charge with opposite polarity at the other interface of the film, e.g., the organic film/cathode interface in the case of the above-mentioned bilayer devices. The polarization charge at the interface can modify the interface properties, such as the energy level alignment and electronic structure [54, 72], and consequently the charge injection efficiency $[18,55]$.

Figure 10 shows the current-density-voltage-luminance $(J-V-L)$ characteristics of $\mathrm{Alq}_{3}$ and $\mathrm{Al}(7-\mathrm{Prq})_{3}$-based devices. The device structure is ITO/ $\alpha$-NPD/Al(7-Prq) $3 / \mathrm{Ca} / \mathrm{Al}$ and $\mathrm{ITO} / \alpha-\mathrm{NPD} / \mathrm{Alq}_{3} / \mathrm{Ca} / \mathrm{Al}$. Note that the polarity of SOP in the $\mathrm{Al}(7-\mathrm{Prq})_{3}$ film is opposite to that in the $\mathrm{Alq}_{3}$ film (Figs. 2 and 5). The conductance of the $\mathrm{Al}(7-\mathrm{Prq})_{3}$ device is remarkably low, which indicates low charge carrier mobilities of the $\mathrm{Al}(7-\mathrm{Prq})_{3}$ film and a high resistance to the charge injection at the interfaces, i.e., $\alpha-\mathrm{NPD} / \mathrm{Al}(7-\mathrm{Prq})_{3}$ for holes and $\mathrm{Al}(7-\mathrm{Prq})_{3} / \mathrm{Ca}$ 

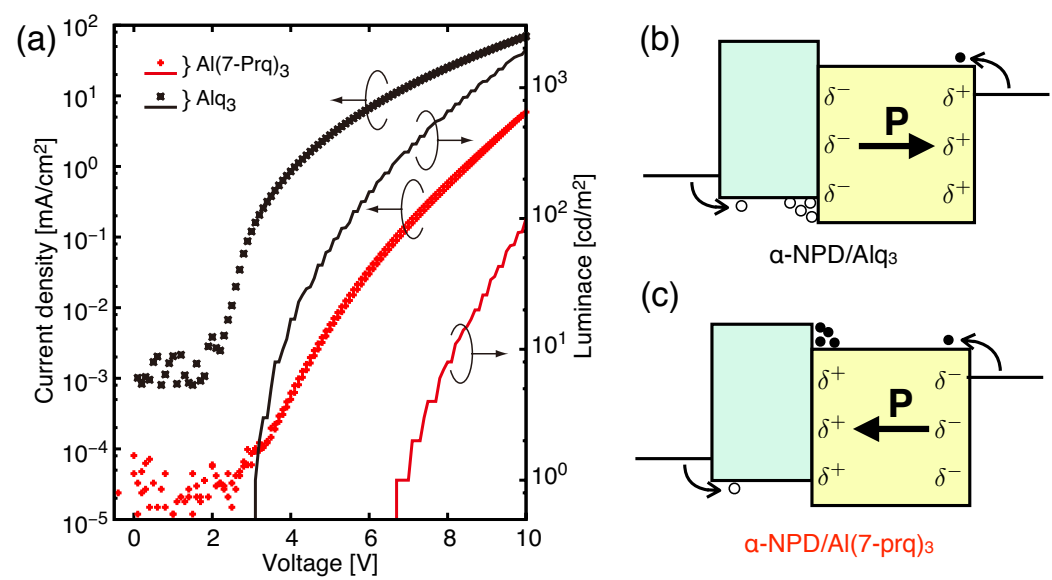

Fig. 10. (a) $J-V-L$ characteristics of ITO/ $\alpha-\mathrm{NPD} / \mathrm{Al}(7-\mathrm{Prq})_{3} / \mathrm{Ca} / \mathrm{Al}$ and ITO/ $\alpha-\mathrm{NPD} / \mathrm{Alq}{ }_{3} / \mathrm{Ca} / \mathrm{Al}$ devices. Adapted from Ref. [18]. (b), (c) Schematic energy diagram of the device in operation. The accumulated charge at the organic heterointerface is hole in the $\mathrm{Alq}_{3}$ device because of the negative polarization charge (b), whereas electron in the $\mathrm{Al}(7$-prq) 3 device (c). At the ETL/cathode interface, the positive polarization charge exists for the $\mathrm{Alq}_{3}$ device (b), while the negative for the $\mathrm{Al}(7-\mathrm{prq})_{3}$ device (c).

for electrons. The low charge carrier mobilities of the $\mathrm{Al}(7-\mathrm{Prq})_{3}$ film are likely because an overlap of molecular orbitals between neighboring molecules may be hindered by the propyl group. Another possible reason of the poor bulk conductivity is insufficient purity of the material, which can be a critical factor to the charge transport characteristics. Moreover, a high resistance to the electron injection at the $\mathrm{Al}(7-\mathrm{Prq})_{3} / \mathrm{Ca}$ interface is suggested by the DCM curves [18].

If we simply assume that the energy barrier for electron injection is the difference between the lowest unoccupied molecular orbital level and work function of $\mathrm{Ca}$, no significant difference is observed between the $\mathrm{Al}(7-\mathrm{Prq})_{3} / \mathrm{Ca}$ and $\mathrm{Alq}_{3} / \mathrm{Ca}$ interfaces [18]. The origin of the high contact resistance can be attributed to the negative polarization charge at the $\mathrm{Al}(7-\mathrm{Prq})_{3} / \mathrm{Ca}$ interface, which is the counterpart of the positive polarization charge at the $\alpha$-NPD/Al(7-Prq) 3 interface (Fig. 10(b) and (c)). The presence of the negative polarization charge can impede electron injection from the cathode to the $\mathrm{Al}(7-\mathrm{Prq})_{3}$ layer. The device simulation based on the drift-diffusion model also revealed that the presence of the positive polarization charge at the cathode interface enhances the electron injection [55]. Altazin et al. reported that the electron density is increased at the electron transport layer (ETL)/cathode interface, when the positive polarization charge is located at the interface. When the polarity is inverted, the electron density is decreased leading to a reduced conductivity of the ETL.

The influence of the polarity of SOP on the charge injection is further supported by the 
(a)

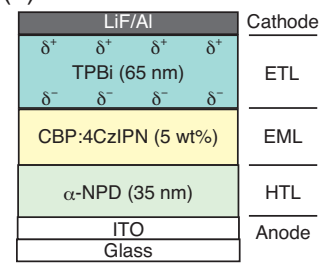

(b)

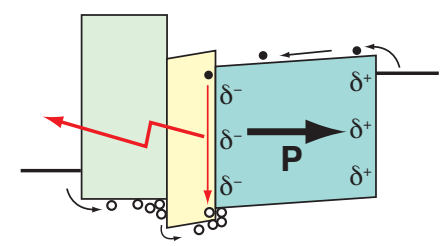

Fig. 11. (a)Schematic illustration of the device structure. (b) Schematic energy diagram of the device in operation.

study of high-sensitivity ultraviolet photoemission spectroscopy. Kinjo et al. reported the direct observation of significantly relaxed negative carriers (anions) at the polar $\mathrm{Alq}_{3}$ film surface [54]. They showed that the electron detachment energy of the anion is about $1 \mathrm{eV}$ larger than the electron affinity of $\mathrm{Alq}_{3}$ measured by inverse photoemission. This significant relaxation energy leads to the good electron injection nature of $\mathrm{Alq}_{3}$.

The polarity of SOP can play an important role for the efficient charge injection, and a film with a positive orientation polarization, which corresponds to a positive polarization charge at the film surface, could be used as an electron injection layer (EIL). Interestingly, the polarity of SOP in ETL and EIL materials ever found are all positive (Fig. 5), that is the preferable polarity for EIL, though they have been selected without knowledge of the relation to SOP.

\subsection{SOP and device degradation}

The apparent interface charge density works as a sensitive probe for device degradation; it decreases proportionally to the loss of luminous efficiency. This relation was first found by Kondakov et al. in an $\mathrm{Alq}_{3}$-based OLED [73], and the following studies revealed similar behavior in other device structures incorporating SOP films [17, 19, 48, 74, 75]. Because the interface charge adjacent to the emission layer (EML) confines the emission zone of the device due to the charge accumulation nature [19], it seems reasonable that the apparent interface charge density is sensitive to the changes (generation of charge traps, change of orientation polarization and so on) in the emission zone. In this section, we show some examples of the degradation properties of OLEDs which include SOP film as an ETL.

The first example is the device doped with a TADF emitter, 4CzIPN [36]. The device structure is ITO/ $\alpha$-NPD/CBP:4CzIPN (5wt\%)/TPBi/LiF/Al (Fig. 11(a)). Because of SOP of the TPBi layer, hole accumulation occurs at the EML/ETL interface at the voltages lower than the electron injection voltage that is around $V_{\text {th }}$. Thus the recombination zone is expected to be confined at the EML/ETL interface (Fig. 11(b)). Because $\alpha$-NPD strongly quenches the triplet exciton of 4CzIPN through Dexter energy transfer [53], keeping the recombination zone far 

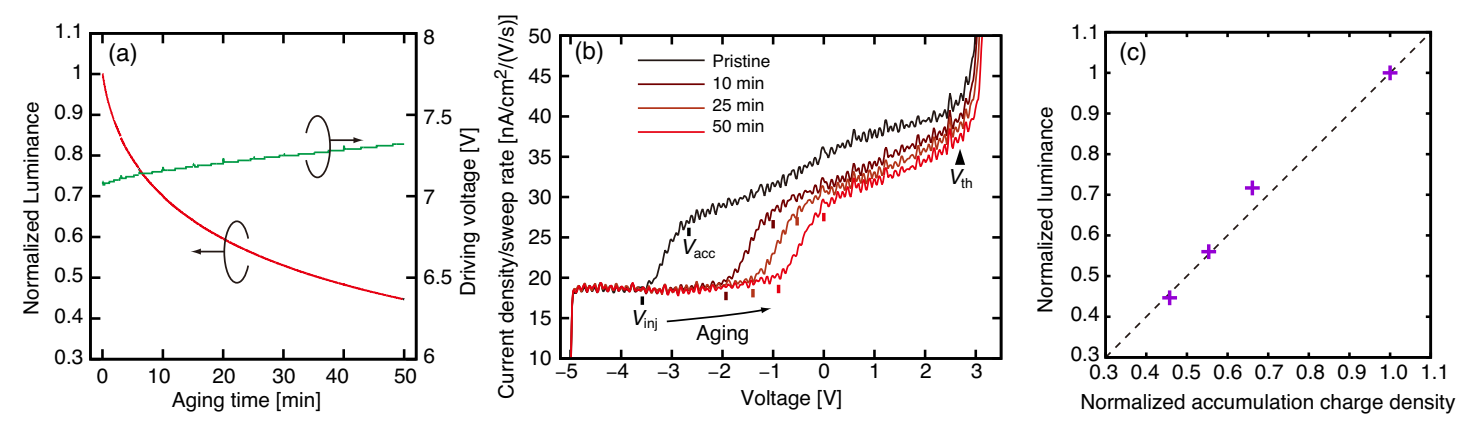

Fig. 12. (a) Aging curves of the doped device at a constant current of $12.5 \mathrm{~mA} / \mathrm{cm}^{2}$. The luminance is normalized by the initial luminance (left axis). The driving voltage is also shown (right axis). (b) Typical DCM curves in the forward sweep of the doped devices at various aging times (10 V/s). (c) Relation between the normalized luminance and normalized accumulation charge density. The accumulation charge density was estimated by integrating the DCM curve from $V_{\text {acc }}$ to $V_{\text {inj }}$ and normalized by the value of the pristine device. The broken line has a slope 1. Reprinted with permission. [18].

from $\alpha$-NPD leads to better EL efficiency.

Figure 12(a) shows the aging curves of this device at constant aging current of 12.5 $\mathrm{mA} / \mathrm{cm}^{2}$. The luminance is normalized by the initial luminance. The normalized luminance decays rapidly although the driving voltage increases slightly, indicating that hole transport layer and ETL did not degrade significantly. Fig. 12(b) shows the DCM curves measured at different aging times. $V_{\text {inj }}$ shifts to higher voltages with device aging, whereas $V_{\text {th }}$ stays at the initial voltage, indicating that $\sigma_{\text {acc }}$ decreased. In Fig. 12(c), we plotted the normalized luminance and normalized $\sigma_{\text {acc }}$ and observed an excellent linear relation with slope equal to one. The result strongly suggests that the charge accumulation is closely related to the luminance loss in the device. Similar linear relations have been reported in devices with polar films such as $\mathrm{Alq}_{3}[17,73-75]$. The charge accumulation often correlates with degradation phenomena in various OLEDs $[48,51]$. Apparently, $\sigma_{\text {acc }}$ evaluation is useful for measuring device degradation.

The reduction in $\sigma_{\text {acc }}$ can be caused by the trapped holes near the EML/ETL interface and disordering of molecular orientation in ETL. Charge traps are often generated during the device degradation, e.g., due to decomposition and chemical reactions of the molecules [48, 51]. The holes captured at such traps compensate the negative polarization charge due to SOP of TPBi, as the result, the apparent interface charge density decays [18, 73]. On the other hand, the molecular orientation, consequently SOP, can be also changed possibly by the high temperature during the device operation due to the Joule's heating and non-radiative recombination [76]. Both cases have been reported, however, the efficiency loss can be attributed to the generation 

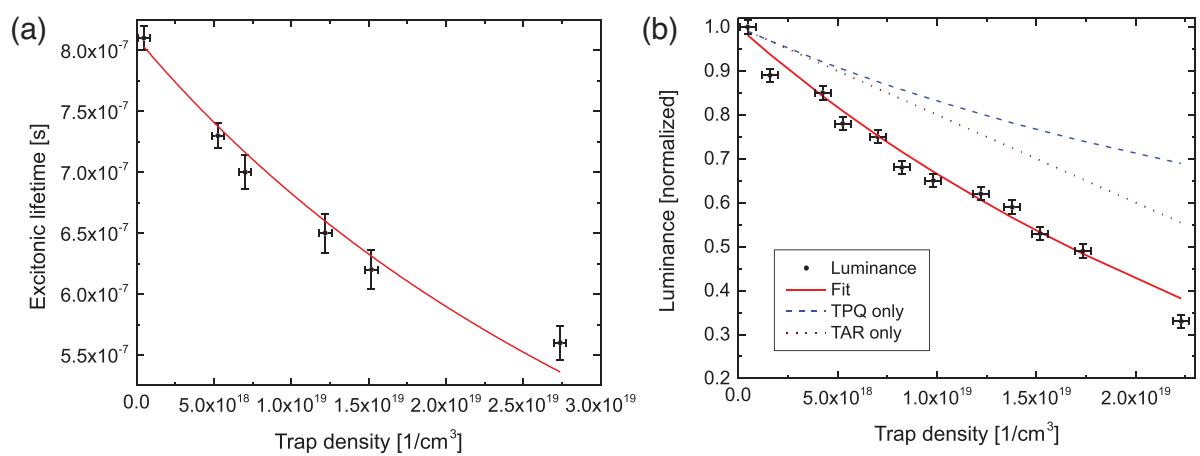

Fig. 13. (a) Dots: Excited states lifetime from TRELS experiments as a function of the trapped charge density determined via DCM investigations. Solid line: Fit of the experimental data using the modified TPQ model. The fit describes the measured date in an excellent way and results in a reasonable value of the TPQ rate of $(0.23 \pm 0.03) \times 10^{-13} \mathrm{~cm}^{3} / \mathrm{s}$. (b) Normalized luminance as a function of trapped charge density (dots). The red line represents the fit including the individual contributions of TPQ (blue dashed line) and TAR (brown dotted line), respectively. Adapted from Ref. [75].

of charge traps.

Schmidt et al. have reported a correlation of the trapped charge density and emission loss in a phosphorescent OLED (Fig. 13) [75]. The device structure they studied was ITO/HATCN/ $\alpha$ $\mathrm{NPD} / \mathrm{Ir}(\mathrm{ppy})_{3}: \mathrm{CBP}(6.5 \mathrm{wt} \%) / \mathrm{BPhen} / \mathrm{Ca} / \mathrm{Al}$, where BPhen exhibits SOP like BCP. They conducted a combination study of time resolved electroluminescence spectroscopy (TRELS) and DCM. The DCM characteristics of this device are basically similar to those of the TADFOLED (Fig. 12), i.e., the charge accumulation occurs at the EML/ETL interface and $\sigma_{\text {acc }}$ proportionally decreased with the luminous efficiency. Although the reduction of $\sigma_{\text {acc }}$ does not directly indicate the presence of the trapped holes as mentioned previously, DCM can also evaluate the trapped charge density by considering the shift in the DCM curves of the first and subsequent triangular voltage sweeps $[19,20]$. The estimated trapped hole density also has a linear relation with the luminous efficiency. The exciton lifetime decay evaluated by TRELS is well explained by considering the non-radiative recombination due to the traps via the triplet-polaron quenching (TPQ) process (Fig. 13(a)) [52]. However, TPQ is insufficient to explain the total luminance loss observed in this device, thus additional mechanisms of the efficiency loss such as trap-assisted recombination (TAR) [77], which deteriorates the carrier balance factor, should also be considered (Fig. 13(b)).

Many of electron transporting and emitting materials exhibit SOP [39]. In the guesthost system, SOP is even enhanced depending on the mixing ratio [42, 43]. In order to properly control the charge distribution around the emission zone, it is necessary to grasp SOP 
characteristics of ETL and EML. The charge concentration at the EML interface confines the recombination zone, leading to fast degradation [53]. Therefore, a broad interface, which is formed by intermixing the EML with ETL, can improve the device stability [78-80], as it dilutes the polarization charge density, and consequently the exciton concentration. Controlling the polarization charge distribution as well as the energy offset by the appropriate choice of the materials and interface design is an important issue to realize the stable operation of OLEDs.

\section{Conclusions}

We have reviewed the current understanding of SOP in the evaporated films of polar organic semiconductors and its influence on the properties of OLEDs. SOP is inherent in the evaporated film of more than several common OLED materials, mainly electron transporters and various kinds of emitters. The results can be extended to many other polar molecules of organic semiconductors. The mechanism of the SOP formation is, however, still incompletely understood. Currently, the short-range van der Waals interaction at the surface during the molecular deposition is suggested to be the driving force of the anisotropic molecular orientation, while the PDM interaction is considered as a negative factor.

Because of the polarization charge induced at the heterointerfaces, SOP modifies the interface properties such as charge accumulation and injection of the device. The interface charge density defines the minimum amount of the accumulated charge during device operation, and that is comparable to the maximum amount of the total charge density. Importantly, the accumulated charge is the real charge while the interface charge is the polarization charge. The emission zone is confined near the charge accumulation interface but the presence of the excess charged species near the emission zone often act as an exciton quencher and induces decomposition of the molecules. Besides the energy level offset and the difference of charge carrier mobilities at the organic heterointerfaces, the charge accumulation properties of the device should be managed taking into account SOP of each layer. On the other hand, the counterpart of the interface charge is located at the organic film/cathode interface, if the polar film is used as the electron injection layer. The presence of the positive polarization charge can enhance the electron injection efficiency. The use of positive GSP materials as EIL is therefore a reasonable choice in terms of the polarity of the film. Although SOP has not been considered as a significant factor to the device performance, in terms of device optimization, the orientational order of PDMs in the film should be taken into account as an intrinsic material property.

It is worth mentioning that SOP is significantly quenched in neat films. There is consider- 
able potential for enhancement of the orientation polarization, though the mechanism to build up GSP needs to be clarified. Controlling SOP based on the molecular design would be an important issue to improve device performance and exploit innovative functions of organic semiconductors.

\section{Material abbrevations}

- Alq 3 : tris-(8-hydroxyquinolate) aluminum

- $\mathbf{A l}(\mathbf{q}-\mathbf{C l})_{3}$ : tris(5-chloro-8-hydroxyquinolinato) aluminum

- Al(7-prq) 3 : tris(7-propyl-8-hydroxyquinolinolato) aluminum(III)

- BAlq: bis(2-methyl-8-quinolinolate)-4-(phenylphenolato)aluminum

- BCP: 2,9-dimethyl-4,7-diphenyl-1,10-phenanthroline

- BPhen: 4,7-Diphenyl-1,10-phenanthroline

- Bpy-OXD: 1,3-bis[2-(2,2'-bipyridine-6-yl)-1,3,4-oxadiazo-5-yl]benzene

- B3PyMPM: bis-4,6-(3,5- di-3-pyridylphenyl)-2-methylpyrimidine

- CBP: 4,4'-bis(N-carbazolyl)-1,1'-biphenyl

- DACT-II: $\quad$ 9-[4-(4,6-diphenyl-1,3,5-triazin-2-yl)phenyl]-N,N, $\mathrm{N}^{\prime}, \mathrm{N}^{\prime}$-tetraphenyl-9Hcarbazole-3,6-diamine

- DCJTB: 4-[dicyanomethylene]-2-tert-butyl-6-(1,1,7,7-tetramethyljulolidyl-9-enyl)-4Hpyran

- $\mathbf{G a q}_{3}$ : tris(8-hydroxyquinolinato) gallium(III)

- HATCN: Hexa-azatriphenylene-hexanitrile

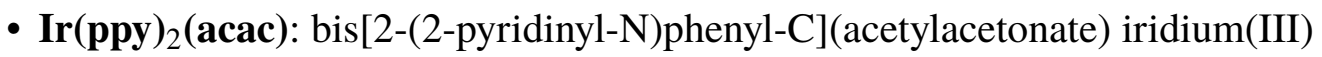

- $\operatorname{Ir}(\text { ppy })_{3}$ : tris(2-phenylpyridine) iridium(III)

- ITO: indium-tin-oxide

- mCP: 1,3-Bis(N-carbazolyl)benzene

- OXD-7: 1,3-bis[2-(4-tert-butylphenyl)-1,3,4-oxadiazo-5-yl]benzene

- TPBi: 1,3,5-tris(1-phenyl-1H-benzimidazol-2-yl)benzene

- UGH2: 1,4-bis-(triphenylsilyl)benzene

- $\mathbf{Z n q}_{2}$ : bis(8-hydroxyquinoline) zinc

- 2CzPN: 1,2-bis(carbazol-9-yl)-4,5-dicyanobenzene

- 4CzIPN: 1,2,3,5-Tetrakis(carbazol-9-yl)-4,6-dicyanobenzene

- 4CzPN: 1,2,3,4-tetrakis(carbazol-9-yl)-5,6-dicyanobenzene

- $\alpha$-NPD: N,N'-bis(1-naphthyl)-N,N'-diphenyl-1,1'-biphenyl-4,4'-diamine (This molecule is commonly termed " $\alpha$-NPD", though the molecular structure is identical to "NPB".) 


\section{Acknowledgement}

The authors gratefully acknowledge to the students and researchers who contributed to the works reviewed in this paper. This research is partly supported by the Japan Society for the Promotion of Science (JSPS) KAKENHI (Grant Nos. 15K13293, and 16H04222), and the Institute of Science and Technology Meiji University, Designated Research, Japan. This work is also granted by Deutsche Forschungsgemeinschaft (DFG; contract no. BR1728/20-1). Furthermore, WB acknowledges JSPS for a BRIDGE Fellowship. The quantum chemical calculations were partly performed using Research Center for Computational Science, Okazaki, Japan.

\section{References}

[1] Various spectroscopic studies on molecular orientation were reported by using vibrational spectroscopy, x-ray absorption spectroscopy, etc. For example, K. Seki, H. Ishii, and Y. Ouchi, in Chemical Applications of Synchrotron Radiation (World Scientific, 2002) Chap. 8, pp. 386-461.

[2] D. Yokoyama, A. Sakaguchi, M. Suzuki, and C. Adachi, Organic Electronics 10, 127 (2009).

[3] D. Yokoyama, Journal of Materials Chemistry 21, 19187 (2011).

[4] D. Yokoyama, A. Sakaguchi, M. Suzuki, and C. Adachi, Applied Physics Letters 95, 243303 (2009).

[5] J. Frischeisen, D. Yokoyama, C. Adachi, and W. Brütting, Applied Physics Letters 96, 073302 (2010).

[6] D. Yokoyama, H. Sasabe, Y. Furukawa, C. Adachi, and J. Kido, Advanced Functional Materials 21, 1375 (2011).

[7] J. Frischeisen, D. Yokoyama, A. Endo, C. Adachi, and W. Brütting, Organic Electronics 12, 809 (2011).

[8] W. Brütting, J. Frischeisen, T. D. Schmidt, B. J. Scholz, and C. Mayr, Physica Status Solidi (a) 210, 44 (2013).

[9] T. D. Schmidt, T. Lampe, M. R. Daniel Sylvinson, P. I. Djurovich, M. E. Thompson, and W. Brütting, Physical Review Applied 8, 037001 (2017).

[10] E. Ito, Y. Washizu, N. Hayashi, H. Ishii, N. Matsuie, K. Tsuboi, Y. Ouchi, Y. Harima, K. Yamashita, and K. Seki, Journal of Applied Physics 92, 7306 (2002).

[11] S. Berleb, W. Brütting, and G. Paasch, Organic Electronics 1, 41 (2000).

[12] W. Brütting, S. Berleb, and A. G. Mückl, Organic Electronics 2, 1 (2001). 
[13] Y. Noguchi, N. Sato, Y. Tanaka, Y. Nakayama, and H. Ishii, Applied Physics Letters 92, 203306 (2008).

[14] Y. Noguchi, N. Sato, Y. Miyazaki, and H. Ishii, Applied Physics Letters 96, 143305 (2010).

[15] Y. Noguchi, N. Sato, Y. Miyazaki, Y. Nakayama, and H. Ishii, Japanese Journal of Applied Physics 49, 01AA01 (2010).

[16] Y. Noguchi, Y. Miyazaki, Y. Tanaka, N. Sato, Y. Nakayama, T. D. Schmidt, W. Brütting, and H. Ishii, Journal of Applied Physics 111, 114508 (2012).

[17] Y. Noguchi, T. Tamura, H.-j. Kim, and H. Ishii, Journal of Photonics for Energy 2, 021214 (2012).

[18] Y. Noguchi, H. Lim, T. Isoshima, E. Ito, M. Hara, W. Won Chin, J. Wook Han, H. Kinjo, Y. Ozawa, Y. Nakayama, and H. Ishii, Applied Physics Letters 102, 203306 (2013).

[19] Y. Noguchi, H.-J. Kim, R. Ishino, K. Goushi, C. Adachi, Y. Nakayama, and H. Ishii, Organic Electronics 17, 184 (2015).

[20] Y. Noguchi, Y. Tanaka, Y. Miyazaki, N. Sato, Y. Nakayama, and H. Ishii, in Physics of Organic Semiconductors (Wiley-VCH, 2012) Chap. 5, pp. 119-154.

[21] K. Kutzner, Thin Solid Films 14, 49 (1972).

[22] L. Onsager, D. Staebler, and S. Mascarenhas, The Journal of Chemical Physics 68, 3823 (1978).

[23] J. Chrzanowski and B. Sujak, Thin Solid Films 79, 101 (1981).

[24] M. J. Iedema, M. J. Dresser, D. L. Doering, J. B. Rowland, W. P. Hess, A. A. Tsekouras, and J. P. Cowin, The Journal of Physical Chemistry B 102, 9203 (1998).

[25] R. Balog, P. Cicman, N. C. Jones, and D. Field, Physical Review Letters 102, 073003 (2009).

[26] O. Plekan, A. Cassidy, R. Balog, N. C. Jones, and D. Field, Physical Chemistry Chemical Physics 13, 21035 (2011).

[27] A. Cassidy, O. Plekan, R. Balog, N. C. Jones, and D. Field, Physical Chemistry Chemical Physics 15, 108 (2013).

[28] A. Cassidy, O. Plekan, R. Balog, J. Dunger, D. Field, and N. C. Jones, Journal of Physical Chemistry A 118, 6615 (2014).

[29] C. Bu, J. Shi, U. Raut, E. H. Mitchell, and R. A. Baragiola, The Journal of Chemical Physics 142, 134702 (2015).

[30] I. K. Gavra, A. N. Pilidi, and A. A. Tsekouras, The Journal of Chemical Physics 146, 104701 (2017). 
[31] T. Manaka, K. Yoshizaki, and M. Iwamoto, Current Applied Physics 6, 877 (2006).

[32] K. Yoshizaki, T. Manaka, and M. Iwamoto, Journal of Applied Physics 97, 023703 (2004).

[33] K. Ozasa, H. Ito, M. Maeda, and M. Hara, Applied Physics Letters 98, 013301 (2011).

[34] K. Sugi, H. Ishii, Y. Kimura, M. Niwano, E. Ito, Y. Washizu, N. Hayashi, Y. Ouchi, and K. Seki, Thin Solid Films 464-465, 412 (2004).

[35] N. Kajimoto, T. Manaka, and M. Iwamoto, Chemical Physics Letters 430, 340 (2006).

[36] H. Uoyama, K. Goushi, K. Shizu, H. Nomura, and C. Adachi, Nature 492, 234 (2012).

[37] C. Adachi, Japanese Journal of Applied Physics 53, 060101 (2014).

[38] H. Kaji, H. Suzuki, T. Fukushima, K. Shizu, K. Suzuki, S. Kubo, T. Komino, H. Oiwa, F. Suzuki, A. Wakamiya, Y. Murata, and C. Adachi, Nature Communications 6, 8476 (2015).

[39] K. Osada, K. Goushi, H. Kaji, C. Adachi, H. Ishii, and Y. Noguchi, Organic Electronics 58, 313 (2018).

[40] T. Isoshima, Y. Okabayashi, E. Ito, M. Hara, W. W. Chin, and J. W. Han, Organic Electronics 14, 1988 (2013).

[41] P. Friederich, V. Rodin, F. Von Wrochem, and W. Wenzel, ACS Applied Materials and Interfaces 10, 1881 (2018).

[42] L. Jäger, T. D. Schmidt, and W. Brütting, AIP Advances 6, 095220 (2016).

[43] T. Morgenstern, M. Schmid, A. Hofmann, M. Bierling, L. Jäger, and W. Brütting, ACS Applied Materials \& Interfaces 10, 31541 (2018).

[44] B. Ruhstaller, S. A. Carter, S. Barth, H. Riel, W. Riess, and J. C. Scott, Journal of Applied Physics 89, 4575 (2001).

[45] M. Matsumura, A. Ito, and Y. Miyamae, Appl Phys Lett 75, 1042 (1999).

[46] F. Rohlfing, T. Yamada, and T. Tsutsui, Journal of Applied Physics 86, 4978 (1999).

[47] D. Taguchi, S. Inoue, L. Zhang, J. Li, M. Weis, T. Manaka, and M. Iwamoto, Journal of Physical Chemistry Letters 1, 803 (2010).

[48] S. Scholz, D. Kondakov, B. Lüssem, and K. Leo, Chemical Reviews 115, 8449 (2015).

[49] R. H. Young, C. W. Tang, and A. P. Marchetti, Applied Physics Letters 80, 874 (2002).

[50] D. Y. Kondakov, W. C. Lenhart, and W. F. Nichols, Journal of Applied Physics 101, 024512 (2007).

[51] F. So and D. Kondakov, Advanced Materials 22, 3762 (2010).

[52] C. Murawski, K. Leo, and M. C. Gather, Advanced materials 25, 6801 (2013).

[53] H. Nakanotani, K. Masui, J. Nishide, T. Shibata, and C. Adachi, Scientific Reports 3, 
2127 (2013).

[54] H. Kinjo, H. Lim, T. Sato, Y. Noguchi, Y. Nakayama, and H. Ishii, Applied Physics Express 9, 021601 (2016).

[55] S. Altazin, S. Züfle, E. Knapp, C. Kirsch, T. D. Schmidt, L. Jäger, Y. Noguchi, W. Brütting, and B. Ruhstaller, Organic Electronics 39, 244 (2016).

[56] N. Hayashi, K. Imai, T. Suzuki, K. Kanai, Y. Ouchi, and K. Seki, IPAP Conf. Series 6, 69 (2004).

[57] M. Kröger, S. Hamwi, J. Meyer, T. Dobbertin, T. Riedl, W. Kowalsky, and H. H. Johannes, Physical Review B 75, 235321 (2007).

[58] D. Yokoyama, K.-i. Nakayama, T. Otani, and J. Kido, Advanced Materials 24, 6368 (2012).

[59] J. W. Sun, J. H. Lee, C. K. Moon, K. H. Kim, H. Shin, and J. J. Kim, Advanced Materials 26, 5684 (2014).

[60] S. Y. Kim, W. I. Jeong, C. Mayr, Y. S. Park, K. H. Kim, J. H. Lee, C. K. Moon, W. Brütting, and J. J. Kim, Advanced Functional Materials 23, 3896 (2013).

[61] K. H. Kim, C. K. Moon, J. W. Sun, B. Sim, and J. J. Kim, Advanced Optical Materials 3, 895 (2015).

[62] J. W. Sun, K. H. Kim, C. K. Moon, J. H. Lee, and J. J. Kim, ACS Applied Materials and Interfaces 8, 9806 (2016).

[63] C. Murawski, C. Elschner, S. Lenk, S. Reineke, and M. C. Gather, Organic Electronics 53, 198 (2018).

[64] M. J. Jurow, C. Mayr, T. D. Schmidt, T. Lampe, P. I. Djurovich, W. Brütting, and M. E. Thompson, Nature Materials 15, 85 (2016).

[65] C. K. Moon, K. H. Kim, and J. J. Kim, Nature Communications 8 (2017).

[66] Y. Noguchi, Y. Nakayama, and H. Ishii, Journal of Vacuum Society of Japan 58, 37 (2015).

[67] H. Ishii, K. Sugiyama, E. Ito, and K. Seki, Advanced Materials 11, 605 (1999).

[68] S. Egusa, A. Miura, N. Gemma, and M. Azuma, Japanese Journal of Applied Physics 33, 2741 (1994).

[69] S. Ogawa, Y. Kimura, H. Ishii, and M. Niwano, Japanese Journal of Applied Physics 42, L1275 (2003).

[70] Y. Noguchi, T. Higeta, and F. Yonekawa, Advanced Optical Materials , 1800318 (2018).

[71] G. G. Malliaras and J. C. Scott, Journal of Applied Physics 85, 7426 (1999).

[72] Y. Nakayama, S. Machida, Y. Miyazaki, T. Nishi, Y. Noguchi, and H. Ishii, Organic 
Electronics 13, 2850 (2012).

[73] D. Y. Kondakov, J. R. Sandifer, C. W. Tang, and R. H. Young, Journal of Applied Physics 93, 1108 (2003).

[74] V. V. Jarikov and D. Y. Kondakov, Journal of Applied Physics 105, 034905 (2009).

[75] T. D. Schmidt, L. Jäger, Y. Noguchi, H. Ishii, and W. Brütting, Journal of Applied Physics 117, 215502 (2015).

[76] T. Miyamae, N. Takada, T. Yoshioka, S. Miyaguchi, H. Ohata, and T. Tsutsui, Chemical Physics Letters 616-617, 86 (2014).

[77] M. Kuik, L. J. A. Koster, G. A. H. Wetzelaer, and P. W. M. Blom, Physical Review Letters 107, 256805 (2011).

[78] Z. D. Popovic, H. Aziz, C. P. Tripp, N.-X. Hu, A.-M. Hor, and G. Xu, Proc.SPIE 3476, 3476 (1998).

[79] J. H. Lee, S. W. Liu, C.-A. Huang, K. H. Yang, and Y. Chang, Proc.SPIE 5464, 5464 (2004).

[80] M. Minagawa and N. Takahashi, Japanese Journal of Applied Physics 55, 02BB08 (2016). 